\title{
The History and Rationale of Daily and Nightly Hemodialysis
}

\author{
Christopher R. Blagg ${ }^{\mathrm{a}}$,Todd S. Ing ${ }^{\mathrm{b}}$, Dennis Berry ${ }^{\mathrm{c}}$, Carl M. Kjellstrand ${ }^{\mathrm{d}}$ \\ a University of Washington, Northwest Kidney Centers, Seattle, Wash., USA; \\ b Loyola University Chicago, Stritch School of Medicine, Maywood, Ill., USA; \\ c Advance Product Development, Aksys Ltd, Lincolnshire, Ill., USA, and \\ ${ }^{d}$ Karolinska Institute, Stockholm, Sweden
}

Quotidian is an adjective that has come into use recently to describe more frequent hemodialysis. However, it would seem appropriate to use the more descriptive terms daily and nightly hemodialysis to describe the time of day that more frequent dialysis is performed. Nightly is to be preferred to 'nocturnal' as three times weekly overnight hemodialysis (also nocturnal) has been a conventional form of treatment since 1964, albeit used by only a small number of patients in recent years. The dictionary definition of quotidian is 'occurring every day' or 'belonging to each day,' but also includes 'commonplace' or 'ordinary'. For the foreseeable future, more frequent dialysis will hardly be either commonplace or ordinary. With regard to the history of quotidian dialysis, a brief review has recently been described [1].

\section{Early History of Dialysis and Acute Renal Failure}

In 1913, Abel et al. [2] performed the first in vivo dialysis of blood in animals at the Johns Hopkins University and suggested that 'a method has been devised by which the blood of a living animal may be submitted to dialysis outside of the body and again returned to the natural circulation'. Cylindrical tubes of collodion, a derivative of cotton, were used as the membrane and hirudin extracted from the heads of leeches was the anticoagulant. This device, dubbed the 'artificial kidney' by a reporter for the Times of London, was modified over the years as better membranes were developed and heparin became available. 
Kolff [cf. 3] developed the rotating drum artificial kidney in 1943 and, using cellophane tubing as the membrane and heparin as the anticoagulant, began treating patients with acute renal failure. For the next 17 years, hemodialysis was used only for the treatment of acute reversible renal failure because vascular access required repeated surgical insertions of cannulas into an artery and vein, thus limiting the number of treatments that could be carried out.

Initially, the need for dialysis in patients with acute renal failure was gauged mainly by the development of signs and symptoms of uremia. After dialysis, some time might elapse before uremic manifestations returned to warrant a repetition of dialysis. Many patients with acute renal failure secondary to accidental or surgical trauma were hypercatabolic, but the interdialytic interval might be prolonged because of anorexia or use of a low-protein diet. However, Teschan's group [4], working in a field hospital behind the front line in the Korean War, showed that patient well-being and survival were improved by what they termed 'prophylactic daily hemodialysis' undertaken before the patient became sick again with uremia. Teschan's 1959 report was the first description of daily hemodialysis.

\section{Chronic Renal Failure}

In 1960, Scribner and co-workers [5] at the University of Washington in Seattle made long-term hemodialysis possible by developing a shunt made entirely of polytetrafluoroethylene (PTFE or Teflon ${ }^{\circledR}$ ) tubing. Between treatments, the arterial and venous cannulas were connected by a short piece of tubing. Because of PTFE's non-stick properties and relative biocompatibility, clotting in the shunt was minimized, enabling many more dialysis treatments before the shunt failed. Six years later, the shunt was superseded by the subcutaneous arteriovenous fistula developed by Brescia et al. [6] in Bronx, New York.

Using the shunt to treat the first patients with chronic renal failure, the Seattle team soon realized that $18-24 \mathrm{~h}$ of dialysis every 5-7 days was insufficient therapy since patients continued to develop uremic symptoms, fluid overload, and hypertension during the interdialytic period [7]. These symptoms and the development of peripheral neuropathy were improved by increasing dialysis frequency to twice weekly with each treatment lasting 10-16h [8]. Nevertheless, the problems of peripheral neuropathy, hypertension, and fluid overload were mitigated only after the first home hemodialysis patients had been dialyzed three times weekly for $8-10 \mathrm{~h}$ overnight [9]. Thus, the regimen of three times weekly hemodialysis was born! Even though this approach involved long, slow dialysis using the Kiil flat-plate dialyzer, the results were more 
impressive than those obtained by programs that used the more efficient coil dialyzers three times weekly for only $4-6 \mathrm{~h}$ per session. With development of even more efficient hollow-fiber dialyzers, the emphasis on a $\mathrm{Kt} / \mathrm{V}$ value of slightly greater than 1.0 as adequate dialysis, further shortening of dialysis time, and the commercialization of dialysis in the USA, it became accepted that most patients continue to suffer from symptoms both during and between dialysis runs.

\section{The First Report of More Frequent Hemodialysis}

The first report on daily dialysis in patients with chronic renal failure was from De Palma et al. [10] in Los Angeles, California. Therapy for 7 home hemodialysis patients was changed to 4- to 5-hour treatments five times per week for up to 3 years. Patient selection criteria included dialysis disequilibrium, cannula malfunction and/or frequent clotting problems, and recurrent severe intradialytic hypotensive episodes. Initially, the patients were treated using Kiil dialyzers but because of the time involved in preparing these, patients were changed to 2- to 3-hour treatments with coil dialyzers using single patient dialysis equipment developed locally for the program. With daily dialysis, the patients' symptoms improved, their appetite increased, they gained weight, and their blood pressure decreased. Unfortunately, the equipment proved very unreliable, the cost of treatment became unsupportable, and the program was abandoned in the early 1970s [11].

\section{The Rationale for More Frequent Hemodialysis - 'Unphysiology’}

In the early 1970s, Kjellstrand et al. [12, 13] investigated factors related to the untoward effects of dialysis. They showed that large fluctuations in body weight, electrolytes, osmolality, and urea concentration were more important with respect to morbidity than concentrations of small uremic toxins or middle molecules. This led them to formulate the 'unphysiology' hypothesis which suggested that wide swings of solutes and fluids in the body were significant causes of morbidity in dialysis patients. Daily or continuous dialysis would more closely mimic the function of the native kidney by reducing the magnitude of solute and fluid oscillations and so would be expected to be superior to the usual intermittent dialysis regimens. This was studied experimentally by Twardowski [14] who showed that increasing the frequency of dialysis from twice weekly to three and then four times weekly, while maintaining total hours 
of dialysis per week constant, resulted in improved hematocrit, blood pressure control, and well-being.

\section{More Frequent Hemodialysis Over the Years}

The next reports came from Snyder's group [15] in Brooklyn, New York, who treated 10 patients with five 2-hour dialyses weekly for a period ranging from 2 months to 7.5 years. This regimen provided a shorter treatment that could be performed before or after work so that patients could devote more time to employment and other activities. Because weekly dialysis time was reduced by one third (from 15 to $10 \mathrm{~h}$ ), pre-dialysis blood urea nitrogen and serum creatinine levels rose. Even so, compared with patients treated three times weekly, patient well-being improved significantly - there were fewer complications, and patients required no transfusions or hospitalizations and had no vascular access complications. However, this program was discontinued because of inadequate reimbursement.

In Italy in 1979, Bonomini et al. [16] in Bologna reported similar benefits in 6 patients treated for 3-4h five times a week for between 6 and 12 months. Symptoms improved, hematocrit rose, transfusion requirements lessened, and hypertension control and cardiac function improved. In 1982, Buoncristiani et al. $[17,18]$ started a daily hemodialysis program in Perugia, Italy, selecting patients with medical indications such as arrhythmias, hypertension, cramps, headaches, and intradialytic hypotension, as well as for social reasons. Despite low values of $\mathrm{Kt} / \mathrm{V}$, the patients showed marked improvements in well-being, muscle strength, hematocrit, hypertension control, cardiovascular stability, and quality of life.

\section{More Frequent Hemodialysis in the Last 10 Years}

In North America, interest in more frequent dialysis was stimulated initially by the work of Uldall and more recently of Pierratos and co-workers $[19,20]$ in Toronto, Canada. This program now has 10 years of experience with long nightly home hemodialysis six or seven nights weekly and has reported extensively on the benefits and most of the issues and problems associated with this treatment. At about the same time, Ting et al. [21] in Mountain View, California, began a program of in-center short daily dialysis to treat patients with serious medical problems and dialysis intolerance [see Ting et al., pp 10-20, this volume]. Despite selection of hard-to-manage patients, most showed marked improvement in their medical condition, tolerance of dialysis, and quality of life. 
As a result of these encouraging reports, there are now probably more than 50 programs in North America providing at least some long nightly or short daily dialysis, usually at home. In the USA, the largest nightly home hemodialysis program was started in 1997 by Lockridge, a nephrologist in private practice in Lynchburg, a small town in rural Virginia. He has now treated more than 40 relatively unselected patients, most of whom are African American. The largest short daily home hemodialysis program in the USA started at the Northwest Kidney Centers in Seattle in 1999 and has treated more than 30 patients. Lindsay in London, Ontario, has a large program using more frequent hemodialysis since 1998 and has published the first and very extensive report on a prospective cohort-matched trial comparing short daily and long nightly hemodialysis with conventional three times weekly treatment [22].

In Europe, a number of physicians outside Italy have also developed programs providing more frequent hemodialysis, usually short daily treatments. These include Traeger and Galland [23] in France and Kooistra and Vos [24] in the Netherlands, as well as others. There are now some 400 papers in the world literature on all aspects of more frequent dialysis while the number of programs and number of patients treated are increasing slowly but steadily. One remarkable feature commented on in many of these papers is that almost all patients who experience the striking benefits of more frequent hemodialysis never want to go back to conventional three times weekly dialysis.

\section{Comments on Short Daily and Long Nightly Hemodialysis}

The two main indications for more frequent dialysis are to maximize wellbeing and minimize both intra- and interdialytic symptoms, as well as to improve the treatment of patients with severe underlying medical problems, particularly cardiovascular disease. With both short daily and long nightly regimens, removing excess fluid from the body becomes a relatively easy task because the amount of such fluid that requires removal during a quotidian session is much smaller than that during a three times weekly session. Short daily dialysis, particularly done in the home, does not disrupt the whole day as much as going to a center for longer dialysis sessions three times weekly. Because post-dialysis fatigue is attenuated, patients can work and act with vigor immediately after dialysis. Long nightly dialysis, also usually done at home, has the advantage of using the hours of sleep for the treatment.

In the course of a conventional 3- to 4-hour dialysis, most of the small molecular weight solutes are removed during the first $2 \mathrm{~h}$ because the concentration gradients of these solutes between blood and dialysate are at their highest during this time. A short dialysis of $2-2.5 \mathrm{~h}$ utilizes only this most fruitful 
period of solute removal. Because of this advantage, the total weekly dialysis time for a conventional three times weekly regimen cannot be equated with that of more frequent short daily dialysis. This was confirmed in a recent report by Williams et al. [25] describing a cross-over study comparing short daily and conventional three times weekly hemodialysis. When the frequency of dialysis treatments was doubled and the time of each dialysis session halved, thus keeping the total hours of dialysis per week constant, significant improvements in well-being, hematologic values, and blood pressure control began to appear within the first 4 weeks of more frequent treatment.

The main difference between short daily and long nightly treatments centers on the ability of the nightly regimen to remove greater amounts of phosphate and $\beta_{2}$-microglobulin. Even so, there is no doubt that both treatments are highly preferable to conventional three times weekly dialysis, and both are effective ways to provide 'adequate' dialysis to very large patients and to achieve a weekly Kt/V value of 6 or 7 in normal-sized patients.

The recently reported HEMO Study showed that with three times weekly dialysis as practiced in the USA, increasing $\mathrm{Kt} / \mathrm{V}$ beyond the minimum recommended by the Dialysis Outcomes Quality Initiative or using high-flux membranes did not improve outcomes, including survival [26]. To date, there is no information on the effect of more frequent dialysis on mortality, but many of the dangerous, potentially lethal complications occur much less frequently, and this would be expected to enhance survival. In addition, there seem to be no additional problems with subcutaneous blood access during quotidian dialysis compared with conventional dialysis, despite a doubling of needle insertions [27].

Time demands on a patient are difficult to deal with if more frequent dialysis is performed in the patient's home using conventional equipment that requires setting up and taking down with each treatment. If done in hospital, short daily dialysis puts increased demands on staff, while nightly dialysis requires opening the unit overnight. Such problems can be reduced by technical innovations. In the case of home hemodialysis, the design issues for patient-friendly equipment are well recognized [28]. A number of new machines are now becoming available that are designed specifically for more frequent hemodialysis and possibly for hemofiltration and/or hemodiafiltration [29]. There are no obstacles, either economic or logistic, for wider application of this superior dialysis method that cannot be overcome by technical innovations.

The cost for dialysis supplies is higher with more frequent dialysis, although this appears to be more than offset by the effects of decreased hospitalization and reductions in the dose of erythropoietin and antihypertensive drugs $[30,31]$. The Dutch government recently recognized more frequent 
hemodialysis as a 'normal' treatment and negotiations are under way with the insurance companies that have responsibility for healthcare reimbursement in the Netherlands. In Canada, where the Ontario Ministry of Health supported both Pierratos' and Lindsay's programs, it is hoped that the Province will also pass legislation to support this treatment. Meanwhile, in the USA, legislation has been introduced into the Congress more than 3 years ago to request the Secretary of Health and Human Services to develop a payment mechanism. This legislation seems unlikely to progress before the next Congress but hopefully will not have to wait several more years for completion of a relatively small study being undertaken by the Center for Medicare and Medicaid Services and the National Institutes of Health.

\section{Scribner's Observations on More Frequent Dialysis}

Perhaps the most perceptive comments on more frequent dialysis were made by Scribner shortly before his death in 2003: 'The goal of more frequent dialysis is to provide the opportunity for all dialysis patients to choose how much time and effort they are willing to devote to dialysis in exchange for better health and well-being, not to mention the marked reduction in adverse symptoms occurring during and between dialysis that comes as an added benefit of increased frequency of dialysis. The effects of more frequent dialysis will be that the annual cost of dialysis will drop. Innovations and automation will make the task of self-dialysis simpler to comprehend and less work for the patient. The resulting healthy, well-nourished, normotensive hemodialysis patients will incur lesser additional health care costs than their sickly, malnourished, hypertensive counterparts on short three times weekly hemodialysis. My mentor, Dr. Randall Sprague, who took care of diabetics at the Mayo Clinic, once gave me the following advice: "A good diabetic should know more about his disease and how it affects him than his doctor." The same advice applies to dialysis patients and especially to the question of how much dialysis each patient needs to feel well.'

\section{References}

1 Kjellstrand CM, Ing T: Daily hemodialysis: History and revival of a superior dialysis method. ASAIO J 1998;44:117-122.

2 Abel JJ, Rowntree LG, Turner BB: On the removal of diffusible substances from the circulating blood by dialysis. Trans Assoc Am Physicians 1913;58:51-54.

3 Van Noordwijk J: Dialyzing for life: The development of the artificial kidney. Dordrecht, Kluwer Academic, 2001. 
4 O'Brien TF, Baxter CR, Teschan PE: Prophylactic daily hemodialysis. Trans Am Soc Artif Intern Organs 1959;5:77-80.

5 Quinton W, Dillard D, Scribner BH: Cannulation of blood vessels for prolonged hemodialysis. Trans Am Soc Artif Intern Organs 1960;6:104-113.

6 Brescia MJ, Cimino JE, Appel K, Hurwich BJ: Chronic hemodialysis using venipuncture and a surgically created arteriovenous fistula. N Engl J Med 1966;275:1089-1092.

7 Hegstrom RM, Murray JS, Pendras JP, Burnell JM, Scribner BH: Hemodialysis in the treatment of chronic uremia. Trans Am Soc Artif Intern Organs 1961;7:136-152.

8 Hegstrom RM, Murray JS, Pendras JP, Burnell JM, Scribner BH: Two years' experience with periodic hemodialysis in the treatment of chronic uremia. Trans Am Soc Artif Intern Organs 1962;8:266-280.

9 Eschbach JW Jr, Wilson WE Jr, Peoples RW, Wakefield AW, Babb AL, Scribner BH: Unattended overnight home hemodialysis. Trans Am Soc Artif Intern Organs 1966;12:346-356.

10 De Palma JR, Pecker EA, Maxwell MH: A new automatic coil dialyzer system for daily dialysis. Proc Eur Dial Transplant Assoc 1969;6:26-34.

11 De Palma JR: Daily hemodialysis: A very old concept. Semin Dial 1999;12:406-409.

12 Kjellstrand CM, Evans RL, Petersen RJ, Rust LW, Shideman J, Buselmeier TJ, Rozelle LT: Considerations of the middle molecule hypothesis. Proc Clin Dial Transplant Forum 1972;2: $127-132$.

13 Kjellstrand CM, Evans RL, Petersen RJ, Shideman JR, von Hartitzsch B, Buselmeier TJ: The 'unphysiology' of dialysis: A major cause of dialysis side effects? Kidney Int Suppl 1975;2:S30-S34.

14 Twardowski Z: Effect of long-term increase in the frequency and/or prolongation of dialysis duration on certain clinical manifestations and results of laboratory investigations in patients with chronic renal failure. Acta Med Pol 1975;16:31-44.

15 Manohar NL, Louis BM, Gorfien P, Lipner HI: Success of frequent short hemodialysis. Trans Am Soc Artif Intern Organs 1981;27:604-609.

16 Bonomini V, Mioli V, Albertazzi A, Scolari P: Daily-dialysis programme: Indications and results. Nephrol Dial Transplant 1998;13:2774-2777.

17 Buoncristiani U, Quintaliani G, Cozzari M, Giombini L, Ragaiolo M: Daily dialysis: Long-term clinical metabolic results. Kidney Int Suppl 1988;24:S137-S140.

18 Buoncristiani U, Fagugli R, Quintaliani G, Kulurianu H: Rationale for daily dialysis. Home Hemodial Int 1997;1:12-18.

19 Pierratos A: Daily hemodialysis: An update. Curr Opin Nephrol Hypertens 2002;11:165-171.

20 Pierratos A: Daily nocturnal home hemodialysis. Kidney Int 2004;65:1975-1986.

21 Ting GO, Kjellstrand C, Freitas T, Carrie BJ, Zarghamee S: Long-term study of high-comorbidity ESRD patients converted from conventional to short daily hemodialysis. Am J Kidney Dis 2003; 42:1020-1035.

22 Blagg CR, Lindsay R (eds): The London daily/nocturnal hemodialysis study. Am J Kidney Dis 2003;42(suppl 1).

23 Traeger J, Galland R, Delawari E, Arkouche W, Hadden R: Six years' experience with short daily hemodialysis: Do the early improvements persist in the mid and long term? Hemodial Int 2004; 8:151-158.

24 Vos PF, Zilch O, Kooistra MP: Clinical outcome of daily dialysis. Am J Kidney Dis 2001;37: S99-S102.

25 Williams AW, Chebrolu SB, Ing TS, Ting G, Blagg CR, Twardowski ZJ, Woredekal Y, Delano B, Gandhi VC, Kjellstrand CM: Early clinical, quality-of-life, and biochemical changes of "daily hemodialysis"(6 dialyses per week). Am J Kidney Dis 2004;43:90-102.

26 Eknoyan G, Beck GJ, Cheung AK, Daugirdas JT, Greene T, Kusek JW, Allon M, Bailey J, Delmez JA, Depner TA, Dwyer JT, Levey AS, Levin NW, Milford E, Ornt DB, Rocco MV, Schulman G, Schwab SJ, Teehan BP, Toto R: Effect of dialysis dose and membrane flux in maintenance hemodialysis. N Engl J Med 2002;347:2010-2019.

27 Kjellstrand CM, Blagg CR, Twardowski ZJ, Bower J: Blood access and daily hemodialysis: Clinical experience and review of the literature. ASAIO J 2003;49:645-649.

28 Kenley RS: Tearing down the barriers to daily home hemodialysis and achieving the highest value renal therapy through holistic product design. Adv Ren Replace Ther 1996;3:137-146. 
29 Pierratos A: Daily hemodialysis - Selected topics. Semin Dial 2004;17:151-173.

30 Mohr P: The economics of daily dialysis. Adv Ren Replace Ther 2001;8:273-279.

31 McFarlane PA: Reducing hemodialysis costs: Conventional and quotidian home hemodialysis in Canada. Semin Dial 2004;17:118-124.

Christopher R. Blagg, MD, FRCP

Professor Emeritus of Medicine

University of Washington

Northwest Kidney Centers, Seattle, WA 98101 (USA)

E-Mail blaggc@hotmail.com 